CATALAN REVIEW

Catalan Review

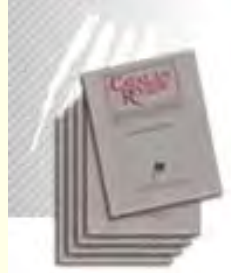

You are accessing the Digital Archive of the Catalan Review Journal.

By accessing and/or using this Digital Archive, you accept and agree to abide by the Terms and Conditions of Use available at http://www.nacs-

catalanstudies.org/catalan_review.html

Catalan Review is the premier international scholarly journal devoted to all aspects of Catalan culture. By Catalan culture is understood all manifestations of intellectual and artistic life produced in the Catalan language or in the geographical areas where Catalan is spoken. Catalan Review has been in publication since 1986 .
NORTH

AMERICAN

CATALAN

SOCIETY
Esteu accedint a l'Arxiu Digital del Catalan Review

A l' accedir i / o utilitzar aquest Arxiu Digital, vostè accepta i es compromet a complir els termes i condicions d'ús disponibles a http://www.nacs-

catalanstudies.org/catalan_review.html

Catalan Review és la primera revista internacional dedicada a tots els aspectes de la cultura catalana. Per la cultura catalana s'entén totes les manifestacions de la vida intel lectual i artística produïda en llengua catalana o en les zones geogràfiques on es parla català. Catalan Review es publica des de 1986.

\title{
«Relació» $i$ «Cobles de la conquista dels fransesos»: textos anònims algueresos del segle $\mathrm{XV}$ August Bover i Font
}

Catalan Review, Vol. VII, number 1 (1993), p. 9-36 


\section{"RELACIÓ" I "COBLES \\ DE LA CONQUISTA DELS FRANSESOS": \\ TEXTOS ANONIMS ALGUERESOS \\ DEL SEGLE XV}

\section{AUGUST BOVER I FONT}

Entre la literatura generada per l'expansió catalana Mediterrània enllà, hom hi pot trobar la Relació i les Cobles de la conquesta dels francesos, textos que descriuen un dels episodis bèl-lics de l'ocupació de l'illa de Sardenya, concretament l'assalt de la ciutat de l'Alguer la nit del 5 al 6 de maig de I4I2 per part del vescomte de Narbona, que els algueresos van desbaratar. Aquests textos han romàs mig oblidats al marge de les històries literàries, i són encara força desconeguts, tot i que el 1869 Manuel Milà i Fontanals els havia donat a conèixer ja a Barcelona,' i que han estat editats - amb intencions diversesunes quantes vegades. ${ }^{2}$

"Lo Gay Saber", núm. XXIX (or.05.1869), 225-226; veg. A. Bover i Font, La represa de relacions culturals amb l'Alguer, "Estudis de Llengua i Literatura Catalanes", II [= Homenatge a Josep $M$. de Casacuberta, 2] (198i), 409-4I6.

${ }^{2}$ Pasquale Tola, Codex Diplomaticus Sardiniae, II (Torí 1868), 46-48 —n'hi ha edició facsímil: (Sàsser 1985) - Manuel Milà i Fontanals, dins La llengua catalana à Sardenya, "Lo Gay Saber», núm. XXIX (oI.05.1869), 225-226; Pier Enea Guarnerio, dins Il dialetto catalano d'Alghero, "Archivio Glottologico Italiano", LX (I886), 285-289; Eduard Toda, La poesia catalana á Sardenya (Barcelona s. a. [I888], II-16 -només les Cobles-, i Un poble català d'Itàlia. L'Alguer (Barcelona 1888) - hi ha la reedició: $L$ 'Alguer. Un popolo catalano d'Italia, amb traducció, introducció i notes a cura de Rafael Caria (Sàsser 198I) - Antonio Sanna, Due testi antichi in dialetto algherese (catalano): "Relacio" e "Cobles de la Conquista des Fransesos", "Anali della facoltà di Lettere, Filosofia e Magistero della Università di Cagliari», XVII (I950), 213-222 — treball reproduït dins: Antoni Ballero de Candia, Alghero, Cara de Roses (Càller 1961), 427-433; Manucl Pagès i Mercader, Estampes de Sardenya (Barcelona 1960), 122-123 (només les Cobles i el començament de la Relació); Pasqual Scanu, Alghero e la Catalogna (Caller 1964) Mussons, Il visconte traditore. Analisi di alcuni aspetti delle "Cobles de la conquista 


\section{LA HISTÓRIA}

Marià V d'Arborea (-1386-1407) era un infant molt petit quan l'any 1387 va succeir el seu germà Frederic $\mathrm{I} i$ no va assumir el govern del jutjat fins l'any 1404, en què va morir Elionor, la seva mare, que havia exercit la regència. Marià, però, va morìr pocs anys després (I407), sense descendència, i no el va succeir el seu pare, Brancaleó Dòria, tot i que ho pretenia, sinó que và ser elegit el vescomte Guillem II de Narbona, que com a nou jutge va prendre el nom de Guillem III d'Arborea, el qual va prosseguir la lluita contra la dominació catalana.

Per aquell temps, a Sicília, Martí el Jove khavia decidit de passar personalment a Sardenya, a fi de posar terme a l'estat en què es trobava l'illa, gairebé d'ençà de la conquestam." Així, l'octubre de 1408 va salpar de Tràpani amb un perit nombre de vaixells, alhora que el seu pare, a Barcelona, feia veure a les Corts l'oportunitat d'intervenir a Sardenya. La campanya va tenir uns bons inicis, els castells de Càller, l'Alguer i Longosardo van ser socorreguts i un petit estol genovès que es dirigia a l'illa va ser capturat. Davant de la imminència del perill, Guillem III va aconseguir la unió amb el comú de Sàsser, els Dòria i els Malaspina.* Amb l'arribada dels reforços de Catalunya, Martí el Jove es va disposar a combatre'Is. La batalla definitiva va tenir lloc a les planes de Sanluri, el 30 de juny de 1409, i Martí, $a \mathrm{mb}$ un exèrcit molt inferior a l'enemic, va vèncer el vescomte $i$ va fer presoner Brancaleó Dòria. Guillem III va poder fugir a Narbona, des d'on va dedicar-se a preparar una nova campanya.

dels fransesos", "Studi Ispanici" (r987/1988), 23-46. No he pogut veure el treball d'Antoni Paba, Un exemple de poesia narrativa a l'Alguer: les "Cobles de la conquista dels francesos", encara inèdit, presentat al col-loqui de l'Associazione Italiana di Studi Catalani La cultura catalana tra l'Umanesimo e il Barocco (Venècia, 24-27.03.1992). Jordi Carbonell fa referència a les Cobles a La llengua $i$ la literatura medieval $i$ moderna, dins Els catalans a Sardenya, a cura de J. Carbonell i Francesco Manconi (Barcelona 1984), 97 -hi ha una versió italiana d'aquest llibre: I catalani in Sardegna (Milà 1984)—. D'altra banda, Antoni Arca n'ha fet diverses edicions divulgatives, inclosa una versió teatral.

${ }^{3}$ Ferran Soldevila, Història de Catalunya (Barcelona $1963^{2}$ ), 538 .

4 Enrico Costa, Sassari, II, primera part (Sàsser 1909), 76. 
Sanluri, evidentment, hauria pogut significar la submissió definitiva de l'illa de Sardenya, però les conseqüències d'aquesta victòria van quedar ben aviat neutralitzades. Martí el Jove va morir a Càller el 25 de juliol de 1409 i abans de l'any, el 3 I de maig de I410, moria també el seu pare, Martí l'Humà, i s'extingia d'aquesta manera la dinastia catalana. Mentre es debatia la qüestió dinàstica, els catalans van defensar com van poder les posicions de Sardenya. Pere de Torrelles, capità general de l'illa a la mort de Martí l'Humà, va procurar de mantenir la situació amb els pocs mitjans de què disposava, i si bé es van perdre moltes d'aquestes posicions, Càller i l'Alguer van resistir. Torrelles va morir de malària, a l'Alguer, el mateix I4IO, però abans de morir va nomenar com a successor Joan de Corbera. I els consellers de Càller, que ignoraven aquest nomenament, van designar com a capità general el comte de Quirra, Berenguer Carròs. Durant un temps tots dos van continuar la lluita, l'un al nord i l'altre al sud, fins que el Parlament de Catalunya va nomenar Ramon Satrilla com a governador del Nord i, una mica més tard, Acard de Mur com a nou capità general de Sardenya (I412).

Mentrestant, el vescomte de Narbona, que després de la mort de Martí l'Humà havia retornat a Sardenya amb noves forces, decidit a ocupar Sàsser i bona part del Logudor - on comptava amb la col-laboració d'una part important de la població-, va arribar fins a Oristany, però no va sentir-se prou fort per mantenir-hi el setge i es và retirar a Sàsser el mes de setembre. Ja en el I4II, va realitzar diverses accions, amb la intenció de penetrar en el territori d'Arborea. I va ser l'any següent que va intentar prendre per sorpresa la ciutat de l'Alguer. Amb l'ajuda dels vaixells del Comte Roig, bastard d'Amadeu VII de Savoia, que li bloquejaven el port alguerès, el vescomte, amb 300 cavallers i i 50 ballesters, entre els quals hi havia nombrosos soldats francesos i ciutadans sasseresos, va assetjar la ciutat la nit del 5 al 6 de maig. Mercès a la foscor, els soldats van poder arribar al peu de les muralles i fins i tot escalar-les, però llavors van ser descobertes per les sentinelles, que van donar l'alarma entre la

5 Veg. F. Soldevila, Op. cit., 656-657. 
població. Els algueresos, que estaven força a l'aguait perquè sabien que els enemics no eren lluny, encapçalats per Ramon Satrilla, aleshores governador del Logudor, es van llançar sobre els enemics als crits d'Aragó! Aragó! i de Muiren, muiren los francesos i.ls traidors dels sassaresos!, i els van encerclar a la torre de l'Esperó, a la qual van calar foc amb l'ajut de les dones, que hi van dur la llenya. Els assetjants van sofrir una gran derrota, amb nombroses baixes, i si el vescomte va poder fugir, el "bastard de Savoia" va ser fet presoner i decapitat l'endemà de l'Ascensió. ${ }^{6}$

La notícia d'aquesta victòria algueresa es va conèixer aviat a Barcelona perquè el dia to del mateix mes de maig hi va arribar la galera de Joan Bartomeu Ferrer, que havia participat en la defensa, enarborant la bandera del vescomte de Narbona, capturada durant el combat. Nou dies després la capital del Principat era l'escenari de la revista passada als 400 cavallers que el Parlament de Catalunya trametia a Sardenya per proseguir la lluita contra Guillem III d'Arborea, a les ordres d'Acard de Mur, nou capità general de l'illa.'

Aquest intent de presa de l'Alguer per part del vescomte de Narbona va encendre l'odi entre algueresos i sasseresos ${ }^{8}$ i va donar origen als textos que ara edito i a la commemoració anual dels fets. Efectivament, tal com diu la Relació, els algueresos "votaren la festa del gloriós apòstol i evangielista sant Juan de la Porta Llatina... y de festegiar-lo tal dia y cantar en versos algunes de les coses memorables e insignes susehides en aquella giornada, a tal reste memòria de tal vitòria y perquè reste fama de la asagna y valor dels nostres

${ }^{6}$ Veg. Jerónimo Zurita, Anales de la Corona de Aragón, llib, XI, cap. 77; Giuseppe Manno, Storia di Sardegna, II (Milà 1835), 92-93; i E. Costa, Op. cit., 77.

7 Veg. la Crònica del Racional de la Ciutat de Barcelona (1334-1417), dins "Recull de Documents i Estudis", I, facicle II (novembre 1921), 174-I75, i F. Soldevila, Op. cit., 657 .

${ }^{8}$ "Aquest tentatiu del vescomte de Narbona, deixà un fons de odis y de rencunies entre Sasseresos y Algueresos, que se perpetuaren fins als nostres dies perquè gran part de les milicies del vescompte, eren compostes de ciutadins de Sásser, y ni un fou perdonat dels vencedors", Ramon Clavellet [= Antoni Ciuffo], L'Alguer, La Sardenya catalana, dins "Catalonia", 22 (28.12.1906), 5 . 
antichs moradors d'esra ciutat...", i la van continuar celebrant ben bé fins l'any 1825 , com ens ho testimonien els documents aplegats en els apèndixs i les informacions que Eduard Toda va recollir entre els vells algueresos. ${ }^{2}$ Durant la festa es disparaven salves, s'encenien focs d'artifici, es cremava un ninot vestit de soldat francès, es feia una processó en la qual es cantaven les Cobles i es passejava els estendards, i durant la missa, després de l'evangeli, de la trona estant es llegia la Relació dels fets. ${ }^{\text {to }}$ No sempre, però, la celebració es va fer d'aquesta manera i moltes vegades els virreis de Sardenya van intentar, en va, d'abolir-la. Així, per exemple, l'any 1628, van aconseguir de prohibir la crema de la imatge del soldat francès."

\section{ELS TEXTOS}

Tant la Relació com les Cobles, mancades ambdues de qualitat literària, semblen compostes en una data molt pròxima als esdeveniments $i$ ens han arribat anònimament en un còdex del segle XVI, conservat a l'Arxiu Municipal de l'Alguer, que duu el títol següent: Còpia auctèntica del libre de les serimònies / dels consellers de la ciutat de Barcelo.lona, I en lo qual al principi stan continuades / algunes cosses que són necessàries saber als consellers d'esta ciutat de l'Alg. I que fins assí se són inviolablement observades. I I586., i que amb la signatura Manuscrit 503 es troba registrat a la pàgina 79 de l'inventari de l'arxiu.

La Relació, que hi ocupa les pàgines $77 \mathrm{r}-78 \mathrm{v}$, és un resum dels fets de la nit del 5 al 6 de maig de I4Iz i fa constar el yot de festejar cada any aquesta victòria.

Les Cobles, que figuren a les pàgines $8 \mathrm{Ir}-83 \mathrm{v}$, descriuen aquests fets en forma versificada i acaben agraint la intercessió de l'apòstol

9 "Hasta en lo mateix sigle en que vivim nosaltres, s'han cantat á Alguer las Cobles de victoria alcansada contra'l de Narbona: los vells del poble me digueren qu'ells las sentiren fins lo any 1825\%, E. Toda, Un poble català d'Italia. L'Alguer, 156.

to Veg. Manuel Pagès i Mercader, Crònica descriptiva d'Alguer (s.l., s.a. [Barcelona 1957], 45 .

"Veg. E. Toda, Un poble català d'Itàlia. L'Alguer, 154-155, i l'apèndix IV d'aquest treball. 
sant Joan. Estan constituïdes per una tornada inicial de quatre versos heptasil.làbics ${ }^{12}$ que rimen $a^{\prime} b^{\prime} c^{3} b^{\prime}$ i ro estrofes d'un nombre irregular de versos heptasil-làbics (les estrofes I i III tenen 9 versos, les VIII i X en tenen I2, la IX en té 8 , i la resta II). Les estrofes acostumen a repetir, a manera de retronxa $\mathrm{i}$ amb algunes variants, els versos
Müiran, müiran los francesos, que han fet la traició al molt alt Rey de Aragó!

$\mathrm{O}$ sigui, que en definitiva totes acaben, amb alguna variant, amb el darrer vers de la tornada inicial: del molt alt Rey de Aragó! L'esquema de les rimes, generalment assonants, és el següent:

\begin{tabular}{|c|c|c|c|c|c|}
\hline I & II & III & IV & V & VI \\
\hline $\bar{a}$ & $\bar{a}$ & $\bar{a}$ & $\bar{a}$ & $a$ & $\bar{a}$ \\
\hline b & b & b & b & b & b \\
\hline a & c & c & a & a & c \\
\hline b & b & b & b & b & b \\
\hline c & c & c & c & c & d \\
\hline$d\left(b^{\prime}\right)$ & d & $\mathrm{b}\left(\mathrm{b}^{\prime}\right)$ & d & d & $\mathrm{e}$ \\
\hline e & $\mathrm{e}$ & d & & & \\
\hline$d\left(b^{\prime}\right)$ & $d\left(b^{\prime}\right)$ & $b\left(b^{\prime}\right)$ & $d\left(b^{\prime}\right)$ & $d\left(b^{\prime}\right)$ & $e\left(b^{\prime}\right)$ \\
\hline $\mathrm{d}\left(\mathrm{b}^{\prime}\right)$ & $\begin{array}{l}\text { f } \\
\text { d (b') }\end{array}$ & b (b') & d (b') & d (b') & $\begin{array}{l}\text { g } \\
\text { e (b') }\end{array}$ \\
\hline & $d\left(b^{\prime}\right)$ & & $d\left(b^{\prime}\right)$ & $\mathrm{d}\left(\mathrm{b}^{\prime}\right)$ & e (b') \\
\hline VII & VIII & IX & $\mathrm{X}$ & & \\
\hline a & a & $a$ & $\mathrm{a}$ & & \\
\hline b & b & b & b & & \\
\hline c & a & c & c & & \\
\hline b & b & b & b & & \\
\hline d & c & a & a & & \\
\hline b & d & $\mathrm{d}\left(\mathrm{b}^{\prime}\right)$ & d & & \\
\hline
\end{tabular}

${ }_{12} \mathrm{Pel}$ que fa al recompte de síl-labes cal tenir present que no sempre s'observen les regles de la prosòdia catalana, com és el cas del vers 8 de la primera estrofa, per exemple: que nos han fet la trai-ció (7 síl-labes). 


\begin{tabular}{|c|c|c|c|}
\hline $\mathrm{e}$ & e & & a \\
\hline b (b') & d & $\mathrm{d}\left(\mathrm{b}^{\prime}\right)$ & $\mathrm{d}\left(\mathrm{b}^{\prime}\right)$ \\
\hline f & a & & e \\
\hline$b\left(b^{\prime}\right)$ & a & & e \\
\hline$b\left(b^{\prime}\right)$ & $f\left(b^{\prime}\right)$ & & d (b') \\
\hline & $f\left(b^{\prime}\right)$ & & $\mathrm{d}\left(\mathrm{b}^{\prime}\right)$ \\
\hline
\end{tabular}

És a dir, doncs, que presenten una estructura semblant a la dels goigs." A l'època de Toda, la música d'aquestes Cobles era ja desconeguda. ${ }^{14}$

La llengua d'aquests textos presenta les característiques pròpies del català oriental, com era d'esperar, ${ }^{15}$ i conté uns pocs castellanismes: asagna, fiels, isla, mengua, pelea.

\section{ELS CRITERIS D'EDICIO}

Transcric escrupulosament el còdex esmentat segons les normes habituals en l'edició de textos catalans antics. He desenrotllat les abreviatures, he regularitzat l'ús de $c$ i $c$ i el de $u \mathrm{i} v$, he indicat amb punt volat les elisions que avui no tenen representació gràfica i he regularitzat l'ús de les majúscules, l'apòstrof, el guionet, l'accentuació, la separació de mots i la puntuació, d'acord amb les normes del català modern, però he respectat les grafies italianitzants, com ara vergie, arcàngiel, ensegnorir, merexien o fexios, per verge, arcàngel, ensenyorir, mereixen i feixos. En el cas de les Cobles he numerat les estrofes.

${ }^{13}$ És conegut l'aprofitament de goigs amb intencions polítiques, veg. Antoni Comas, Història de la literatura catalana, IV (Esplugues de Llobregat 1972), 44. Justament els goigs van ser una de les aportacions culturals catalanes a l'illa de Sardenya, i durant el segle XIX, a l'Alguer, l'estrofisme dels goigs s'havia utilitzat per impetrar la pluja en temps de secada, veg. A. Bover i Font, Els goigs sards, dins Els catalans a Sardenya, 105-110, i Dos goigs sardo-catalans: sant Baldiri de Caller i la Verge del Roser, dins "Estudis de Llengua i Literatura Catalanes", XxvII [=Miscel-lània Jordi Carbonell, 6] (1993), 95-1ro.

${ }_{14}$ "Aquestas coplas tenian sa música. Recordan las narracions antigas que sacompanyavan ab molts instruments, mes, per desgracia, eixa música no es avuy coneguda.n, E. Toda, Un poble catalì d'Itàlia. L'Alguer, $15 \mathrm{I}$.

${ }^{i 5}$ Veg. J. Carbonell, La llengua i la literatura medieval $i$ moderna, dins Els cataLans a Sardenya, 96. 
LA *RELACIO

Relació de la victòria que los algueresos tingueren en lo ayn $I_{4} I 2$, en lo jorn de St. Juan de la Porta Llatina. [77r]

En nom de l'onipotent Déu y de la gloriosa vergie Maria y dels benaventurats arcàngiel sant Miquel y apòstol y evangelista sant Juan, patrons d'esta ciutat de Alguer.

Memòria sia per lo esdevenidor com en lo ayñ I4I2, en semblant die de vui, essent esta ciutat. com vui és, dels sereníssims Reis de Aragó, de imortal recordassió, y governant de governador en esta ciutat $y$ en tot lo present cap de Llogudor mossèn Ramon Satrilles, vingueren los francesos, enemichs de la Corona de Aragó, y per llurs caps y capitans lo bisconde de Narbona y lo bastart de Saboya, los quals, volent-se ensegnorir d'esta ciutat, en tal nit com esta vingueren ab tant silensi y secret que escalaren las morallas, del que, essentse avists les sentinelles y guàrdies, tocaren a l'arma. Y com los moradors y [77v] abitadors estàvan apersebits, per tenir com tenian los enemichs a prop, foren encontinent a punt, ab sas armas, ballestres y vergues, y trobaren ya los enemichs [que] havian entrada la terra, y resistint-los ab gran valor y esfors daren en ells, y aprés de gran pelea los retiraren y astringieren en la torre de l'Esparó, siguint lo esfors y valor de llur capità y governador, lo qual, axí bé estava nafrat, no per ço afluxià ni desamparà la batalla, ni dexià de fer tot ço y quant a bon capità convenia, apellidant: Aragó, Aragó! Muiren, muiren los francesos y los trabidors dels etc., y posaren foch en la torre de Esperó, hont se éran retirats, en lo qual conflite, les dones, ab gran coragie y varonil ànim del que merexien per tot temps gran llaor, agiudaren ab fexios de rama y brandons en las mans, acudiren per a posar foch en dit lloch, y a l'últim fonch [78r] nostre Senor servit dar vitòria als nostres, ab gran mortaldat dels enemichs, entre los quals restà presoner lo bastart de Saboya, llur capità, al qual li fonch llevat lo cap lo endemà de la Assensió del Señor, del dit ayñ, en la plassa que se diu de sant Esteve, ${ }^{*}$ en lo carrer de sant Antoni.

* Hi ha un forat al lloc de l'última vocal. 
Per la qual vitòria, havent-la coneguda de mans de l'onipotent Déu y Seńor nostre, havent-li fetes gràsies com a bons cristians, votaren la festa del gloriós apòstol y evangielista sant Juan de la Porta Llatina, essent estada en son die, lo qual<s> és de creure fonch intercessor devant del Señor per alcansar-la, y de festegiar-lo tal dia y cantar en versos algunes de les coses memorables e insignes susehides en aquella giornada, a tal reste memòria de tal vitòria y perquè reste fama de la asagna y valor dels nostres antichs moradors [78v] d'esta ciutat, la qual nos sia sempre per espill de voler-los imitar en ser fiels y leyals al nostre Rey y señor y defensar ab lo matex valor y esfors la nostra pàtria y ciutat contra* los que semblant atreviment voldran tenir, fent gràssias y dant llaors al Señor y a l'apòstol y evangielista sant Juan per haver-la lliurada en tal dia de tal invasió, suplicant-lo humilment nos vulga ser advocat y intersesor devant la divina Magestad, que la vulla guardar a ella y tots sos ciutadans de tot perill y sinistre. Amén.

\section{LES "COBLES"}

\section{[81r] Cobles de la conquista dels fransesos}

$O$ visconte de Narbona,

bé haveu mala rahó

de, vós, escalar la terra

del molt alt Rey de Aragó!

\section{Co[bla]}

I. Escalada la aveu sens falla mes lo Alguer bé hos ha costat, los millors homes de armes los llurs caps y han dexiat, ab molta ballestraria $y$ vergadas ab baldó,

* Afegit al marge. 
dient: Múiran los francesos, que nos han fet la traició, del molt alt Rey de Aragó!

\section{Co[bla]}

[8Iv]

II. Lo Monseñor de l'altura, que n'és novell capità aquell que à pres la enpresa, $\mathrm{ab}$ mossèn Sissilià, de toldra a nós la terra falsament a traysió. Gran fore estada la mengua de la Casa de Aragó.

Múiran, muiiran los francesos, que n'àn fet la traició al nostre Rey de Aragó!

\section{Co[bla]}

III. Defensada nos han la terra, los albergans ab gran rigor, quant veeren lo mur combatre.

Cetrillas, governador, aquell que nefrat estava, mostrà gran esfors y bo, dient: Múiran los francesos, que nos han fet la traició al nostre Rey de Aragó!

\section{Co[bla]}

[82r]

IV. La bandera haveu dexada, visconte, mal vostre grat. Virgili, que la portava, de bona n'és escapat. Ferit fonch de un colp de glavi 
y nefrat de un virató, prestament saltà la escala a sercar son compañó. Múiran, múiran...

\section{Co[bla]}

V. La trompeta que aportàvan poch li valgué son sonar ne l'assalt que atocàvan, ca sert no hi gòsan montar, ans fugí $a b$ lo visconte quan ell veu la destrució que faïan* dels francesos en la torre de l'Esparó. Múiran, múiran...

\section{Co[bla]}

VI. En lo bastart de Saboya no hos y cal pas esperar, que gia més castells ni vilas no veureu pas escalar, puix que en lo Alguer sens falla pengiat lo han com un lladró y tolta li han la testa lo endemà de la Asensió. Muiran, múiran...

\section{Co[bla]}

[82v]

VII. De les dones vos diré diñas són de gran llaor, quals tingueren gran coragie defensant al llur señor.

* Lectura difícil. 
Aportàvan totas lleña, cascuna ab son brandó, per metre foch a la torre que se apella lo Esparó, dient: Múiran los francesos, que han fet la traició al nostre Rey de Aragó!

\section{Co[bla]}

VIII. O traidors de sassaresos, ara no hus caldrà clamar, que los vostres amichs francesos són vinguts a visitar.

França!, França!, haveu cridada, molts francesos haveu vist, y per tota vostra vida per traidors sareu tenits. Múiran, múiran los francessos $y \cdot$ ls traidors de sassaresos, que han fet la trayció al molt alt Rey de Aragó!

\section{Co[bla]}

IX. O bisconte de Narbona, no hos y cal pas a tornar, que en la isla de Sardeńa no porreu res heretar, mas tornà-vo'n en mal.hora en Narbona a fer traició, si no voleu que hos lleve la testa lo molt alt Rey de Aragó. Múiran, múiran...

X. Grans llaors li sian donadas a l'apòstol sant Joan, 
la* de la Porta Llatina.

Fem-li festa cascun añy

aquell que per nós pregava,

tots fasam-li oració,

que suplique a Déu lo Pare

que nos guarde de traició.

Múiran, múiran los francesos

$y \cdot$ Ls traidors de sassaresos,

que han fet la traició

al molt alt Rey de Aragó!

Finis

AUGUST BOVER I FONT

UNIVERSITAT DE BARCELONA

* Llegiu: lo. 


\section{APËNDIXS}

\section{I \\ RELACIO DELS DETALLS DE LA CELEBRACIÓ \\ DE LA FESTA (mitjan s. XVI)}

\section{La salve se ha de fer per la festa de Sant Joan de porta llatina axi la nit com lo matí en la professó y despres dinar al cantar la cansó.}

La nit se fan los fochs al tocar de la oració y se tira divuyt mortarets y dos peces y la matexa nit dos dotzenes de cohets voladors y los fochs grechs se repartexen ab alguns cavallers y ciutadans y se tiran la matexa nit y se fá una granada y una trompa.

Item lo endema de matí á la professó se tiran dotze morterets y dos peçes y se tiran una dotzena de cohets voladors y una roda.

Item lo dit die al despres dinar quant se canta la cansó se tiran divuyt mortarets y dos peçes y tres dotzenes de cohets voladors y se fa una statua de un frances plena de artiffiçis de foch.

Item se fan axibe una dotzena de cohets corradors ab corda y se repartexen entre la nit lo matí á la professó y al despres dinar á la cançó.

Notta la polvora se ha de dar per fer la contra scrita festa.

Primo, per quaranta y vuyt mascles á sinch sous per mascle y per llensar per terra, 4 lliuras.

Item per les sis peçes á 9 lliures per peça, 54 lliures.

Item per dotze dotzenes de fochs grechs, $\mathrm{y}$ sis dotzenes de voladors, 26 lliures.

Item per dos rodes y una granada, 20 lliures.

Item los cohets de las cordas la nit y á la professó quant se canta la cansó (en blanch).

Item per lo françes, 5 lliures.

Item una rima de paper per los cohets y fochs grechs.

Item quatra lliures de fil per dits cohets y demes artifficis.

Item se dona un caxo y mig mistos per dits artiffissis.

Eduard Toda, Recorts catalans de Sardenya (Barcelona, s.a. [1887]), 8-9. 
RELACIÓ DE MÉS DETALLS DE LA FESTA

(final s. XVI)

Item la vigilia del die de St. Joan de porta llatina á 5 de maig se fan fochs á la nit y se tiran 24 mascles y tres pesas y lo die de dit Sant á sis de maig se fa professo y se canta la cansó dels francesos en la porta de la casa de la ciutat. Y se tiran altres tres pesas y 24 mascles, ço es vuyt mascles y huna pesa al portal real, al baluart de la madalena altres vuyt mascles y huna pesa y al castellás (torre del Esperó) altres vuyt mascles y una pesa. Y mes dotze dotzenes de fochs grechs, coets vuyt dotzenes de corradors y quatre dotzenes de voladors, una Roda, una espasa y una granada, ço es la nit la trompa y la mitat dels coets y la granada, y lo die la roda ab laltre mitat dels coets. Y se fan los personatjes de Sant Joan y Sant Miquel que van ab la professó dit die y los angels, y se portan las banderas de la ciutat.

Eduard Toda, Recorts catalans de Sardenya (Barcelona, s.a. [I887]), 9-Io. 


\section{III}

ANTON JAUME - SECRETARI MUNICIPAL

DE L'ALGUER DEL SETEMBRE DE 1608

AL 24 DE JUNY DE 162I-VA ANOTAR

QUE ANDREU BACALLAR - BISBE DE L'ALGUER ENTRE I578 I I6O5- VA REDUIR TOTS ELS VOTS

DE LA CIUTAT A CINC, ENTRE ELS QUALS

ES MANTENIA LA COMMEMORACIÓ

DE LA FESTA QUE ENS OCUPA.

Lo die de Sant Joan de portallatina es festa per solemnitat.

Eduard Toda, Recorts catalans de Sardenya (Barcelona, s.a. [1887]), II. 


\section{IV}

ADDICION y EXPOSICION sobre el Dialogo dicho en la libertad del Françes, ossea Françoi que cada año suele quemar la noble Ciudad de Alguer... librado solamente por el año I 628 a peticion de sus hijos los de Saçer

\section{Françes}

Heu me miserum

Quia vilis factus sum!

EXPOSITIO

Si mis hijos no me vieran

Padeçer tantos dolores

Mis males fueran menores,

Ni ellos deshonra tuvieran.

D.n Miguel Comprat Sassares

Noli timere, quiq qui tetigit te, tanget pupillam oculorum meorum.

\section{EXPOSITIO}

No os dejaré padeçer

Pues soy vuestro hijo honrado

Porque el morir vos quemado

Fuera afrenta a mi hazer.

\section{Françes}

Spes mea tu in die afflictionis

Libera me, quia Pater tuus sum. 


\section{EXPOSITIO}

Tu mi esperansa eras

En esta mi affliçion

Tu mi gran Consolaçion

Tu mi bien, mi querer eras.

D.n Miguel Comprat Sassares

Unam petii a Domino hanc requiram.

\section{EXPOSITIO}

Una cosa sola pido

Y sola esta he de buscar

Que no se deje afrentar A mi Padre tan querido.

\section{Françes}

Si hoc fuerit unguentum, effusum erit nomen tuum.

EXPOSITIO

Hijo seras medicina, Cura tuya, y de mi mal, Si de una afrenta tal Libras esta alma mesquina.

D.n Miguel Comprat Sassares Orans pro Rege Sassarensi Pro Gallo; ne uratur Domine, $\mathrm{Ne}$ des patrem meum in perditionem. 


\section{EXPOSITIO}

El amor paterno es tal,

Que es fuerza a mi que le pida

Que no sufra por su vida

En mi padre tan gran mal.

\section{El Baron Manca Sassares}

Non credebam narrantibus mihi donec ipse vidi; ne facias Domine opprobium nostrum.

\section{EXPOSITIO}

Muchas vezes no he creydo

Lo que ahora veo aqui,

$\mathrm{Y}$ pues lo veo vengo a ti

Señor, que le libres pido.

$$
\text { D.n Gaspar Pilo Sassares }
$$

Vide Domine afflictionem meam, Considera quia ego tecum sum.

\section{EXPOSITIO}

Grande afrenta se me haze

Señor en su campañia,

$\mathrm{Y}$ si bien jusga no es mia

Si esso a su Excellençia plaçe.

D.n Bernardo Sanna Alguerés

Domine ne corrumpas insignia. 


\section{EXPOSITIO}

Señor es antiguedad

Que a costumbra en este dia

Hazer con grande alegria

Aquesta Noble Ciudad.

\section{El Baron de Sorso}

Patres nostri manducaverunt uvam acerbam, et Parentes nostri destructi sunt.

\section{EXPOSITIO}

Nustros Padres causa fueron

Que esta afrenta nos suframos,

$\mathrm{Y}$ pues hijos nos hallamos,

Paciencia pues lo hisieron.

\section{El Governador de Capudoro}

Propter delicta eveniunt nobis mala; sed libera nos a malo.

\section{EXPOSITIO}

Verdad, que son nuestros males

Causa de nuestra verguenza

Però, Señor, indulgençia

Que nos libre de otros males.

\section{Gracia obtorgada del Virey a los Sassareses}

en favor de su Padre

Vos qui sequuti estis me, eruam vos de ignominia vestra, et Patrem vostrum salvare faciam. 
EXPOSITIO

No sufre Persona Real

Deshonra en sus servidores,

Y pues los soíjs Señores

No sufriré cosa tal.

\title{
ADDITIO
}

Pues tengo bien conoçido

Que nunca me haveis dejado,

Haré que no sea quemado

Vuestro Padre tan querido.

\author{
VOCATIO \\ Venga D.n Fran.co amado \\ Que el hará mi embajada \\ A los Iurados, y haga \\ Que el Françes no sea quemado.
}

\section{MISSIO}

Señor, vaya de mi parte $\mathrm{Al}$ Señor Iurado en Cabo, $\mathrm{Y}$ diga, que soy rogado, Que el Françes no se maltracte.

A los otros diga assi

Pues estan halli presentes, Que es rason a tales gentes Se satisfaga por mi.

INSTANTLA

Si disen, que no es rason 
Se quite esta antiguedad,

Diga le den libertad,

Qu esta es mi resoluçion.

Nobilis D.n Franciscus Amat nuntial sibi exposita

\section{EXPOSITIO}

Señores vengo embiado

De parte de Su Excelencia

Que al Françes se de indulgençia

Y que no sea maltratado.

Dicho me lo han, y rogado

Los Señores Sassareses

Como hijos de Franceses

Que el Padre no sea quemado.

El D.r Vellino Sassares, y Iurado Segundo

Quam dulcia auribus meis eloquia tua!

EXPOSITIO

O dulce hablar que hase

Señor D.n Fran.co Amado,

Pues soy Segundo Iurado

Lo haré porque me plaçe.

Los quatro Iurados de Alguer responden a D.n Fran.co Amat

Durum est contra stimulum calcitrare.

EXPOSITIO

Pues requiere $\mathrm{Su}$ Excellencia

Que el Frances no sea quemado, 
Señor D.n Fran.co Amado, Le diga buena paciencia.

SUPER EXPOSITIONEM

Pues que ganar no podemos

Si contra de el contrastamos

Per esta vez le libramos

$\mathrm{Y}$ otras dos lo quemaremos.

D.n Fran.co Amado

Sic honorabitur quemcumque voluerit Rex honorare, ne indignatio eius super nos veniat.

\section{EXPOSITIO}

Desta suerte será honrado

Quien a su Dueno obedesse

Si mereçe, o no mereçe

No busquemos tal cuidado.

El Señor Obispo Machin Algueres

Liberate eum quia ipse vult.

\section{EXPOSITIO}

Pues no quiere sea quemado

Le libre con regosijo,

Y mi Sobrino, que es el hijo

Se de en su casa recado.

Los Iurados de Alguer

Solvite eum, sinite abire. 


\section{EXPOSITIO}

Que se desate el Françes

Mandamos, et hoc in quantum

Possumus pro hac vice tantum,

Que es desir por esta vez.

Los muchachos de Alguer

Ecce maledictus, lapidemus eum.

\section{EXPOSITIO}

Pues tus hijos te han librado

Maldit Françes traydor

Aora has de morir peor

Moriras apedreado.

Escrive Alguer a Caller

Fecit redentionem plebis suae.

\section{EXPOSITIO}

Hise la redempcion

Saçer de su Padre honrado

Pues a quemar condenado

Fue libre a su peticion.

Responde Caller a Alguer

Inimicus ero inimicis tuis, et odiantes te disperdam.

EXPOSITIO

Pues que Saçer redimio

A su Padre tan querido 
Le sea comun enemigo

Que otro y tanto haré yo.

SUPER EXPOSITIONEM

Por proximo no le tengo

Pues de mi está lontano,

$Y$ pues a ti es sercano

Has lo que a desir te vengo.

Satis etc. etc. etc.

Pasquale Tola, Codex Diplomaticus Sardiniae, II (Torí 1868), 48-50. 


\section{V \\ REBUT DE NICOLAU CANU (1678), CONSTRUCTOR I PINTOR DEL NINOT D'AQUELL ANY}

He rebut yo Nicolao Cano, pintor, de Mestre Francisco Saillas, conseller quint, quatre lliures treze sous per la factura y peinta de lo francés esseptuat la tela que la te dada lo negoci de don Gavi olives, y per que constia fas fer lo present de ma de altri y fermada de la mia. Alguer a 2 de Maig 1678.

-Nicola Canu.

Pier Enea Guarnerio, Il dialetto catalano d'Alghero, "Archivio Glottologico Italianon, LX (1886), 290.

Eduard Toda, Un poble català d'Itàlia. L'Alguer (Barcelona 1888), I55. 


\section{VI \\ NOTES DEL CANONGE QUERQUÍ \\ SOBRE AQUESTA CELEBRACIÓ (1748)}

Funcion y procession el dia de S. Juan ante Portam Latinam.

A seis de Mayo de cada año el Cabildo con assistencia del Magistrado, todas las Religiones Cofradías y Gremios haze por voto Procession general por la victoria, que en semexante dia los Moradores desta Ciudad tuvieron contra los Franzeses: y se cantan dos motetos, el uno en la calle, eo plaza de la Iglesia de S. Antonio Abad, donde sucedió la victoria, y fué degollado el bastardo de Saboya general de dichos Franzeses; y el otro en la puerta de la casa de la Ciudad, donde se conservan los Estandartes de dichos Franzeses los que en estos años passados dos de los matriculados llevavan á caballo, precediendo á la Procession, y de pocos años á esta parte han dexado de llevarlos por ser muy laceros y raidos, y en la Procession se canta el himno Tristes erant Apostoli, etc.; peró en la plassa de S. Antonio Abad se empieza despues el Motete, el hymno Te Deum laudamus, concluido el qual se buelve al primer himno Tristes, etc.; y en la Iglesia Cathedral se canta el versículo y oracionn de gracias y la Missa Canonical de S. Juan ante Portam Latinam.

Eduard Toda, Un poble català d'Itàlia. L'Alguer (Barcelona 1888), I55-I56. 


\section{VII}

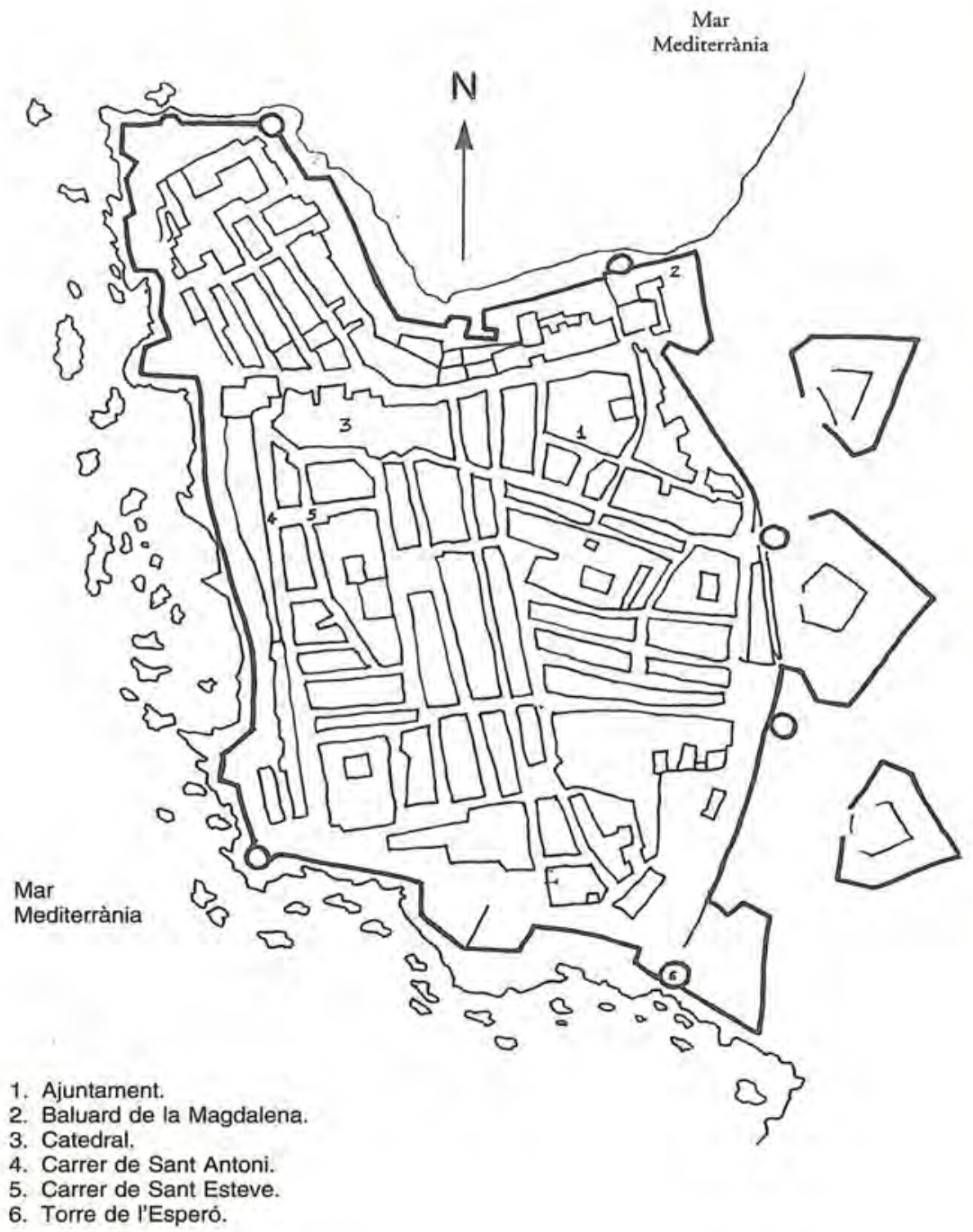

Plànol de l'Alguer, que correspon aproximadament al segle XIX, on són localitzats els topònims esmentats en aquest treball. 